
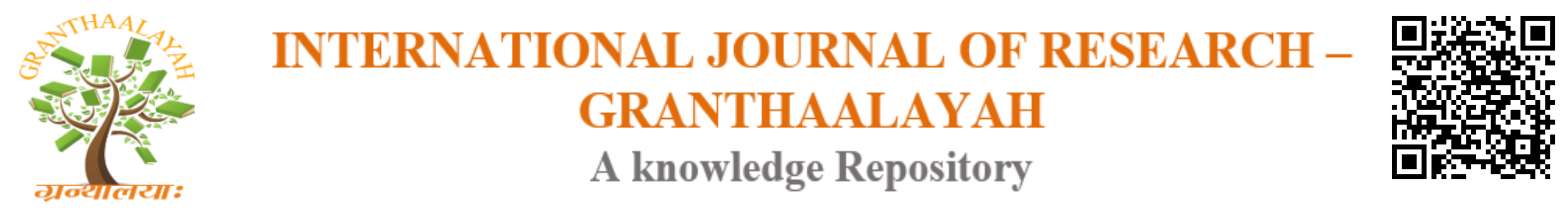

Management

\title{
ETHICALLY PRACTICED UNETHICAL STRATEGIES IN PHARMA INDUSTRY - WHOM TO BE BLAMED
}

\author{
V. Sasirekha ${ }^{* 1}$ \\ ${ }^{* 1}$ Professor - Ph. D, Sri Sairam Institute of Management Studies, Sri Sairam Engineering \\ College, Chennai - 44, India
}

\begin{abstract}
As the competition is getting more intense, the number of instances of companies alleged to have been involved in illegal and unethical practices is increasing at an alarming rate. Being an integral part of the society, business organizations have certain duties, responsibilities, and obligations toward the society, referred to as "Business Ethics". The pressures of the reality challenges the ethical frameworks traditionally followed by organizations. The global pharmaceutical industry is highly regulated, capital intensive, and driven by large research and development expenditures. Despite the pharmaceutical industry's notable contributions to human progress, it is fraught with ethical challenges. This paper presents the ethically practiced unethical strategies that are followed in the industry referencing the case studies of mega corporations and concludes the need for "systematic training in ethics" for all the stakeholders and the need for ethical leadership in an organization.
\end{abstract}

Keywords: Business Ethics; Pharmaceutical Industry; Evergreening; Ghostwriting; Biased research.

Cite This Article: V. Sasirekha. (2018). "ETHICALLY PRACTICED UNETHICAL STRATEGIES IN PHARMA INDUSTRY - WHOM TO BE BLAMED.” International Journal of Research - Granthaalayah, 6(2), 32-45. https://doi.org/10.5281/zenodo.1186096.

\section{Introduction}

As the competition is getting more intense, compounded by globalized economy, the number of instances of companies alleged to have been involved in illegal and unethical practices is increasing at an alarming rate. An unprecedented number of executives of fortune 500 companies either are convicted or are under investigation at present. Ethics refers to well-founded standards of right and wrong that prescribe what humans ought to do, usually in terms of rights, obligations, benefits to society, fairness, or specific virtues (Manuel Velasquez et al) ${ }^{1}$. "Business Ethics" is applied ethics and defined as the critical, structured examination of how people \&

\footnotetext{
${ }^{1}$ Manuel Velasquez et al., "What Is Ethics?," Santa Clara University: Markula Center for Applied Ethics, 2010, accessed October 7, 2011,www.scu.edu/ethics/practicing/decision/whatisethics.html.
} 
institutions should behave in the world of commerce. Ethical issues, such as bribery and corruption, are evident throughout the world and many national governments and international agencies are actively attempting to minimize such actions through economic sanctions and international codes of ethical behavior. "Business ethics is the art of applying ethical principles to examine and solve complex moral dilemmas" ${ }^{2}$.

Ethics within organizations is necessary and should be initiated by the top management and percolate to the bottom of the hierarchy. Being an integral part of the society, business organizations have certain duties, responsibilities, and obligations toward the society, which further provides them with an opportunity to conduct business. The business leaders and employees of the organization must carry out their activities in a responsible manner to balance their business, society, and their reputation. With the growing number of corporate scandals coming to light, business schools all over the world have recognized that corporate misconduct and criminality is caused due to the lack of training in business ethics. The scandals, swindles, irregularities, and violations committed by the organizations are perplexing for society causing it to instantly react to such deviant business practices.

The scandals of Enron, Tyco, Earnest \& Young, J.P. Morgan, Merrill Lynch, Xerox, Boeing Corporation, Lehman Brothers and the fraud committed by the CEO of Satyam computers, the arrest of Chung Mong-Koo, chairperson of South Korean automobile giant, Hyundai, for unethical business practices ${ }^{3}$, clearly illustrate the perilous consequences of corporate misconduct which has not only ruined these organizations but also has wounded the society and the country at large. They have done irreparable damages to their stakeholders. Companies following ethical practices can double their profits and show high market capitalization than the companies' not practicing ethics. Honesty, integrity, and transparency are the touchstones of business ethics. Transparency leads to accountability, truth, commitment to justice and public integrity. There are a number of reasons about why the businesses should act ethically: To protect its own interest, to protect the interests of the business community and to create a trust among public, to keep its commitment to society, to meet the expectations of stakeholders, to prevent harm to the public etc.

\subsection{Present Business Scenario \& the Challenges Faced in Following Ethics}

The astonishing developments in information and communications technology in the recent years such as advancement of the internet, mobile telephony, wireless communication, and digital information systems have transformed the world. While many of the consequences are undoubtedly positive, the changes have also brought with it immense pressures on the way organizations function and individuals work and respond to each other. The pressures of the reality have not only changed the way the work is done but has also challenged the ethical frameworks that have been traditionally followed. With these changes, several ethical issues are to be faced and solved by the organizations to the satisfaction of their stakeholders. Owing to the

\footnotetext{
${ }^{2}$ Joseph W. Weiss, Business Ethics: A Stakeholder and Issues Management Approach (Orlando, FL: Harcourt Brace College Publishers, 1988), p. 7.

${ }^{3}$ Fackler, M. \& Sang-Hun, C. (2006, May 17). Chairman of Hyundai is charged with theft. The New York Times. Retrieved from http://www.nytimes.com/2006/05/17/business/worldbusiness/17hyundai.html
} 
business growth, the organizations function with flat structure leading to decentralization of authority and decision making to lower levels of an organization. The process of decentralization leads to a number of ethical issues in the organization. Conflicting goals of individuals and organizations are the root causes of several unethical practices and challenge ethical decisions.

\section{Pharmaceutical Industry}

The global pharmaceutical industry is a multinational industry that is a highly regulated, capital intensive, and driven by large research and development expenditures. The industry is privately owned and is technologically sophisticated. As there are many diseases prevalent in the community of the globe, drugs are essential to cure them. The pharmaceutical industry develops, produces, and markets drugs, used as medicines. The total unaudited and audited global pharmaceutical market size was US\$ 962.1 billion for the year 2012 with a $2.4 \%$ growth rate and the CAGR \% is expected to be 5.3\% for the period 2012 - 2017 (C2013 IMS Health Inc.). ${ }^{4}$ Moreover, the global pharmaceutical industry revenue is forecasted to reach an estimated US $\$ 1,226.0$ billion by 2018 , with a steady growth rate. The industry is expected to register growth led by ageing population, changing lifestyles, hectic daily activities, unhealthy eating habits and the increasing incidence of chronic diseases and new diseases across the entire global population.

In the global market, the position of the pharmaceutical industry is not the same as compared to other IT based industries. The total world pharmaceutical market is covered mainly by US, Japan, France, Germany, UK, Italy, China, Canada, Spain, Brazil etc. ( IMS, Health) ${ }^{5}$. The total pharmaceutical sales of the top ten companies accounts for more than $40 \%$ of the total market. The 10 largest drugs companies control over one-third of this market, several with sales of more than US\$10 billion a year and profit margins of about 30\%. Emerging markets such as China, South Korea, Brazil, Russia, and Turkey has experienced double-digit growth, signaling an important shift occurring in the pharmaceutical industry.

\section{Unethical Practices in Pharmaceutical Industry}

The issue of unethical pharmaceutical marketing practice has received a great deal of attention in recent years, prompting many doctors associations, pharmaceutical industrial associations, and individual corporations to engage with the issue. Many have passed codes of conduct and ethical guidelines for the marketing of pharmaceuticals; however if not monitored and enforced, their impact will be limited. One of the reasons for the vulnerability of pharmaceutical industry towards corruption is heavy regulation. Heavy regulation is essential not only to safeguard the population against sub-standard drugs and unfairly priced goods, but also to ensure that the industrial policies strengthen economic competitiveness of the pharmaceutical sector and improve innovation and efficiency. These two objectives can sometimes lie at cross-purposes, if regulators are subject to pressure from commercial groups such as generous political campaign donations and lobbying expenditures by pharmaceutical companies. The following is the quick rundown of various unethical practices followed in the pharmaceutical industry.

\footnotetext{
${ }^{4}$ http://www.nasdaq.com/markets/ipos/filing.ashx?filingid=8836005

${ }^{5}$ http://www.imshealth.com/portal/site/imshealth
} 


\subsection{Evergreening Practices}

"Evergreening" refers to the strategies whereby pharmaceutical companies use patent laws and minor drug modifications to extend their monopoly privileges on the drug (Dwivedi \& Hallihosur, 2010 \& Rangan et al, 2009 \& Wertheimer \& Santella, 2009). Typically, these strategies are developed before expiry of the patent of an original drug, usually a high-revenue drug (Whitehead et al, 2008 \& Hutchins, 2003). If obtained, it results in an extension of the patent protection period or a new patent for a minimally modified version of the drug and enables the innovators to retain monopoly over its product even after expiry of patent term. The innovators usually bring in small changes and then claim patent rights for 20 years.

Evergreening strategies commonly adopted by the pharmaceutical industry are:

1) Redundant extensions and creation of 'next generation drugs' which result in superfluous variation to a product and then patenting it as a new application

2) Prescription to over-the-counter (OTC) switch

3) Exclusive partnerships with generic drug players in the market prior to drug patent expiry which thus significantly enhancing the brand value and interim earning royalties on the product.

4) Defensive pricing strategies practice wherein the innovator companies decrease the price of the product in line with the generic players for healthy competition

5) Establishment of subsidiary units by respective innovator companies in generic domain before the advent of rival generic players.

Consequences of Evergreening: A consequence of evergreening is the delayed entry of generic drugs into the market with extension of the original drug patent or competition between the patent-protected minimally modified version of the drug and generic drugs (Hemphil \& Sampat, 2012). This situation might increase drug reimbursement costs by keeping the cheaper generic versions completely or partly out of the market (Faunce \& Lexchin, 2007). Pharmaceutical companies defend evergreening practices and claim that revised formulas benefit patients and the drug industry (Hughes D, 2006 \& Gaudry KS, 2011). Extending the patent period seizes generic drug manufacturing. Once generic drugs are under production, the price of the drug can drop by as much as $90 \%$. Additional costs incurred through delay in generic entry can be very significant for the public health budgets and ultimately the consumer.

Ethical Issue: The net cost for society of evergreening patents is substantial. Evergreening patents interfere and hinder fair competition in the pharmaceutical market, with the result that pharmaceutical companies can charge high monopoly prices for far longer period than is justified.

Case 1 - Evergreening of Patents - Case of Novartis

On April 1, 2013, India's Supreme Court rejected Novartis Patent Application for the cancer medication- Gleevec (Glivec). This high-profile case, not only ended Novartis seven-year battle in India, but also represented a bigger battle over generic drugs both overseas and in the U.S. In 2005, as a requirement of admission into the WTO, India reenacted patent protections for intellectual property. Until that change in Indian Patent Law, Indian pharmaceutical companies freely produced medicines pioneered by foreign drug companies at a fraction of the cost. The 
Indian patent office stated that generic manufacturers are entitled to make their own versions of a patented medication and pay a royalty to the patent holder, given the patented medication is not made available at a reasonable price in the Indian marketplace. Novartis Gleevec's U.S. patent expired in 2015, meaning that, other generic-drug manufacturers can join the Indians in their ability to produce Novartis medication. Anticipating this, Novartis has already engaged in "evergreening" by introducing a new slightly modified formulation of the older drug in order to effectively maintain patent protection. India's Supreme Court rejected Novartis "evergreening" on the basis that the formulation was not significantly inventive, different, or better than previous drugs on the market. As a result, Indian pharmaceuticals may continue producing Novartis medication generically and sell it in India at a fraction of the Swiss drug's cost.

Source: http://www.lexology.com/library/detail.aspx?g=97441a81-b27b-43aa-a8eebf2522339cf0/ Novartis A.G. V Union of India - The Gleevec Case and Evergreening http://www.lawyerscollective.org/news/archived-news-a-articles/126-novartis-case-backgroundand-update-supreme-court-of-india-to-recommence-hearing.html

\subsection{Publication Planning and Ghost Management}

Within the pharmaceutical industry, the term describes the finely calibrated process by which clinical trials, commentaries, and other articles supporting the efficacy of particular products are written and released in the biomedical literature. The controlled production and release of preclinical studies, clinical trials, reviews and, commentaries may begin years before a drug is launched. Peer-reviewed clinical efficacy studies supporting a new drug or a new indication for a commercially available drug are considered "primary" or "core" publications. Sponsored articles can be difficult for journal editors and readers to spot. To ensure that articles are well written and contain suitably subtle marketing messages, a pharmaceutical company may enlist the assistance of a professional medical writer. Such assistance ranges from editing to ghostwriting (i.e., writing contributed by authors who are not acknowledged when the article is published).

Industry-funded ghostwriting: It is the practice whereby drug companies pay medical writers to write drafts or final versions of research articles and then seek out academics to become the identified authors. Ghostwritten articles are strategically placed and designed to give the publications the appearance of objectivity when, in fact, they conceal pervasive conflicts of interest. The whole process of publication planning designed by industry is described by Sergio Sismondo as "ghost management," of which the ghostwriting is only one component of an invisible process (Sismondo, 2008). Industry-sponsored ghostwriting may take at least three forms:

Ghostwriting for Collaborative Research: It is a technical write-up of clinical research sponsored by a pharmaceutical company in which a medical writer is engaged through a contract with a medical education communications company (MECC). The named 'authors' of the paper are academics or clinical investigators who might contribute to the design of the trial, carry out the collection of data from the sites of the trial, and participate in revisions of the drafts of the manuscript that is produced by the medical writer. While some of these academics qualify for authorship status, others are offered pure 'honorary' authorship. The medical writer of the draft is acknowledged in the fine print for "editorial assistance" or "manuscript preparation." One of the main problems with this type of ghostwriting is misreporting of the data to favor the sponsor 
company's product. The control of the message remains with the sponsor company rather than with the named academics on the published paper.

Ghostwriting for Paid Honorary Authors: Pharmaceutical companies frequently use in-house medical writers to produce manuscripts, which are then offered to an 'honorary' academic author to affix their name before the paper is submitted for publication (Fugh-Berman, 2005). These publications are typically, but not always, review articles. In this type of ghostwriting, the signed 'author' has played no role in the research or the writing of the paper, and may or may not revise the paper. However, the actual writer is not acknowledged. Honorary authors are typically 'key opinion leaders' - the industry term for academics who are sought by pharmaceutical companies because of their credentials and their ability to influence other prescribers. Key opinion leaders are crucial to the promotional strategy of the company. In the attempt to gain dominance in the market share for a blockbuster drug or to fight 'competitive issues, the companies compensate key opinion leaders to have their names appear on ghostwritten articles and letters that focus on the weakness of competitors' drugs (McHenry, 2005).

Ghostwriting Articles on Prescribers' Experiences with Drugs: Companies also create ghostwriting programs specifically to build product loyalty among prescribing physicians by providing them with opportunities to publish. Pharmaceutical sales representatives visit the prescribing physicians and encourage those who have had favorable experiences with the drugs to liaise with a medical writer to produce a draft of a paper. Many of these publications have appeared in the literature as case studies.

Ethical Issues: The ethical issues related to ghostwriting in the corporate world are complex and multi-faceted. Ghostwriting is ethically defensible when both the ghostwriter and bylined author collaborate to create a piece of communication to meet the goals of an organization. A collaborative process serves the needs of the executive who may have top-notch ideas but subpar writing skills, as well as the needs of the ghostwriter who has the superior writing skills and the drive to serve the organization.

Case Study 2 - Ghostwriting Case

Back in 2008, it was revealed that Wyeth Pharmaceuticals (presently part of Pfizer) paid ghostwriters to compose articles hyping the supposed benefits of its hormone replacement therapy (HRT) drug, and solicited academics to stamp their names on them claiming authorship. The forged articles then appeared in prestigious journals where thousands of doctors ended up reading and absorbing the information as if it was independent, evidence-based medicine (http://www.naturalnews.com/News_000614_Wyeth...). GlaxoSmithKline (GSK) named its ghostwriting program "CASPPER" (Case Study Publication for Peer Review), and recruited medical scientists to be the "authors" of studies promoting their best-selling drug. The acronym's similarity to the name of a famous cartoon ghost 'Casper' was apparently no accident. SmithKline Beecham budgeted for 50 articles under the CASPPER program in 2000 alone (Hill, 2009). Between 2000 and 2002, articles from the CASPPER program appeared in five medical journals. Later Glaxo had published a list of fees paid out to US healthcare professionals for speaking and consulting services for the three month period of April 1, 2009 to June 30, 2009. From the records, Glaxo paid $\$ 14.6$ million to approximately 3,700 US doctors and other 
healthcare professionals. The figures are direct payments by GSK, and do not include payments made by its contracted firms, like STI.

\subsection{Industry Funded Biased Research}

A systematic review found that studies funded by pharmaceutical companies were four times more likely to have outcomes favoring the sponsor than were studies with other sponsors (Lexchin et al., 2003). There is a big difference between industry-funded research and other independent research. The source of funding tends to play a major role in the outcome of any study. Drug research sponsored by the pharmaceutical industry is more likely to end up favoring the drug under consideration than studies sponsored by government grants or charitable organizations. When physicians base their prescribing decisions on such biased (or worse) information, the patients' health is clearly at risk. Most pharmacoeconomics (economic evaluations of medical studies) are conducted in-house either by the drug companies or externally by consultants who are paid by the company (Koren, 1991; Perlis, 2005). Results that are unfavorable to the sponsor-that is, trials that find a drug is less clinically effective, cost effective, or less safe than other drugs used to treat the same condition-can pose considerable financial risks to companies. Pressure to show that the drug leads to a favorable outcome may result in biases in design, outcome, and reporting of industry-sponsored research (Hauck, 1986).

At least three possible explanations exist for favorable results seen in industry-sponsored research. Firstly, pharmaceutical companies may selectively fund trials on drugs that they consider superior to the competition. Secondly, positive results could be the consequence of poor quality research conducted by industry. For example, low quality trials exaggerate the benefits of treatment by an average of 34\% (Moher et al,1999 \& Moher et al, 1998). Thirdly, selecting an appropriate comparator is a key issue in planning a clinical trial (Bero LA,Rennie D, 1996 \& Djulbegovic B,Lacevic M,Cantor A,Fields KK,Bennett CL,Adams JR, et al, 2000 \& Djulbegovic $\mathrm{B}, 2001)$. In the study by Rochon et al., in most cases in which the doses of the study and comparator drugs were not equivalent, the drug given at a_higher dose was that of the supporting manufacturer (Rochon et al, 1995). As the authors saw, higher doses may bias the results in favor of the effectiveness of the manufacturer's product. There are many clever ways that companies use to manipulate their research (Sackett et al, 2003), and two recently published books provide dozens of examples (Gotzsche, 2013 \& Goldacre, 2012). Flaws in the coding of adverse events can distort results without leaving any trace of what has happened, as we cannot get access to the raw data that is in the hands of the drug companies.

Ethical Issue: Industry critics argue that drug companies ensure positive results by subtly biasing the research designs of their studies. Supporters counter that the methodological quality of industry-supported studies is unusually good, and that the trend of positive results may mean that companies choose to do research on drugs that they know are effective.

Case Study - 3 - Pfizer - Research Funding and Positive Publication Bias

Research into internal company documents has revealed that Pfizer Inc., the world's largest research-based pharmaceutical company, tampered with the results of at least 16 study reports on its epilepsy drug. To expand the market for the drug, Pfizer unlawfully removed, altered, and changed published study findings that revealed unfavorable results. Of the 20 study reports that 
were produced, eight were not published in medical journals at all and another eight had their original study designs altered in some way in order to arrive at alternate outcomes. Some of the primary outcomes were changed to new ones while others were replaced by secondary outcomes. Others were simply removed altogether, to arrive at favorable results. Industry-funded research trials are often altered, forged, and manipulated to suit the cause, as was the case with Pfizer. When Pfizer was sued in 2004 for illegally promoting a drug, it settled the case for $\$ 430$ million.

http://www.naturalnews.com/027692_science_fraud_Neurontin.html\#\#ixzz2qfSsZdUh

Pfizer caught in yet more science fraud: Company altered findings for drug E. Huff, staff writer

\subsection{Positive Publication Bias}

Drug companies are under no obligation to publish the results of research they have funded. A recent analysis found that a third of antidepressant trials conducted for FDA approval were never published, and most of these were negative (which means that there was no difference between drug and placebo) (Turner E et al., 2008). Publication bias is a major problem in the medical literature (Callaham M, 2001 \& Koren G, 1991). Generally studies with positive outcomes are more likely to be published than studies with negative outcomes (Dickersin K, 1990). Negative outcomes are defined as randomized clinical trials (RCTs) which fail to find statistically significant benefit, with an active treatment as opposed to a control group in an adequate sample size (Hauck WW, 1986). The non-publication of negative outcomes in RCTs is reported to occur in pharmaceutical industry-funded studies, as opposed to studies funded by governmental sources (Perlis RH, 2005 \& Davidson RA, 1986 \& Finucane TE, 2004). In the past few years, manufacturers have attempted to prevent studies which are unfavorable to their products from being published in several high profile cases (Rennie D, 1997 \& Nathan DG,Weatherall DJ, 1999 \& McCarthy M, 2000). To conclude, oftentimes, medical journals or pharmaceutical companies that sponsor research will report only "positive" results, leaving out the non-findings or negative findings where a new drug or procedure may have proved more harmful than helpful.

Ethical Issue: Publication bias deceives clinicians by cherry picking only the positive data, giving the appearance that a drug is more effective than it actually is.

\subsection{Prescription Data Mining}

Drug companies purchase information from pharmacies about doctors' prescribing habits and use this information to target particular doctors in their sales calls and other marketing efforts. Given the high costs of detailing efforts, drug companies employ the most efficient ways. For their existing drugs, companies like to know which physicians are already prescribing the drugs, so they can reinforce the physicians' preferences. In addition, companies like to know when a physician switches from the company's drug to a competing drug, so the company can encourage the physician to switch back (J. L. Klocke, Comment, 2008). The practice of prescription datamining dates back to the early 1990's, when prescription records went digital. Pharmaceutical companies use the records to determine which doctors are more susceptible to various kinds of sales messages, doctors prone to using new drugs, "brand loyal" physicians to a certain manufacturer, doctors to be rewarded for their prescribing practices with high paying consultancies, advisory board positions, and scholarships to "educational" seminars. Access to 
prescribing data stoked a massive increase in spending and sales force size for individualized marketing.

Ethical Issues: First, prescriptions are part of medical records that document private decisions made in the context of the doctor patient relationship. Permitting commercial use of these records injects marketing influence into the exam room. Secondly, drug marketers are exerting undue influence over the prescribing practices, which is contributing to irrational prescribing practices that harm public health and unnecessarily raise the cost of health care. Third, access to this data is corrupting the medical profession by allowing companies to use advisory board appointments, consultancies, and gifts as direct payment for observed prescribing practices. Finally, access to individualized data means promoting the use of harassing and vexatious sales practices in which sales representatives attempt to hold doctors "accountable" for gifts and promises to complete and achieve their sales targets. All of these purposes provide ample justification for state regulation in this area, regardless of any "free speech" arguments raised by the industry.

\subsection{Gifts to Doctors}

Drug companies have traditionally given doctors gifts, ranging from pens and lunch to trips. The more lavish gifts have been banned by the American Medical Association's ethics policy for some time. Nevertheless, gifts no more than $\$ 100$ in value is allowed by AMA guidelines. The pharmaceutical industry spends about $\$ 12$ billion every year on gifts and payments to physicians (Studdert DM, Mello MM, Brennan TA, 2004). The goal of spending all this money is to get physicians write more prescriptions for a particular company's product. This money may be spent on educational programs, small gifts, or meals for the physician. In 2001, a Henry J. Kaiser Family Foundation random survey of physicians found that 92 percent of physicians received free drug samples from pharmaceutical companies; 61 percent received free meals, tickets for entertainment or free travel; 13 percent received "financial or other in-kind benefits"; and 12 percent received financial incentives to participate in clinical trials (Blumenthal D, 2004). Pharmaceutical representatives do provide a lot of information about new products but most of this information is heavily biased in the favor of products. The important issue with this type of marketing is the increase in costs. As each company attempts to outdo the previous one, costs continue to increase. These costs are then added into marketing budgets of the pharmaceutical companies and ultimately appear in the prices of the drugs, thereby increasing healthcare costs for everyone.

Ethical Issue: Critics cite evidence that even small gifts create a feeling of obligation in the physician, who may be consciously or unconsciously influenced in prescribing habits (Wazana, 2000).

Case Study 4- GlaxoSmithKline Beecham

GlaxoSmithKline (GSK), the drug maker, pushed a drug aggressively and unethically from the drug's entry onto the market in 1992. In July 2012, GSK plead guilty to federal criminal charges of bribing doctors with gifts and money, hiding safety information from the FDA and the public, and running faulty studies on the drug. In July 2012, GSK was ordered to pay a $\$ 3$ billion fine to the US government for its dishonest behavior in the promotion and marketing of the drug. This is 
the biggest fine the US government has ever imposed on a pharmaceutical company. $\$ 3$ billion is still only a fraction of the profits GSK made on the drugs in the suit.

Source: http://www.dandell.com/dangerous-drugs/paxil-lawsuit/.

\subsection{Industry-Funded CME}

The pharmaceutical industry funds greater than half of the costs for continuing medical education (CME). They are responsible for providing more than 70 percent of the funding for clinical trials (Studdert DM, Mello MM, Brennan TA, 2004). In fact, studies show that pharmaceutical company sponsored CME always preferentially highlighted the sponsor's drug (Wazana A, 2000). Continuing Medical Education is meant to inform physicians in an unbiased manner. CME sponsored by pharmaceutical companies afford the drug companies the opportunity to market its' products by disguising the marketing as an educational event. The problem is that the pharmaceutical industry is funding a large portion of these events. In 2003 pharmaceutical companies were providing $\$ 900$ million of the $\$ 1$ billion spent annually on continuing medical education in the United States (Blumenthal D (2004)).

Ethical Issue: Critics argue that this is an inherent conflict of interest, and that it inevitably leads to education biased in favor of the sponsor's products.

Case study 5 - Warner Lambert

In a whistle-blower lawsuit in federal court in Boston, a former employee of Warner-Lambert Co. has accused the company of hand-picking speakers and signing off on their presentations about unapproved uses of an epilepsy drug. Independent education providers prepared the courses, which was given around the country. The suit claims that by means of its role in continuing education, among other actions, Warner-Lambert caused doctors to write inappropriate prescriptions in 1998. That, in turn, cost the Medicaid insurance program for the poor hundreds of millions of dollars, the suit claims. Warner-Lambert was acquired by Pfizer in 2000.

Source: http://online.wsj.com/news/articles/SB1038953904187251993

\subsection{Promotional Speaking}

Drug companies hire prominent physicians to give promotional talks for other doctors. Spending on promotional speaking dropped to $\$ 13.2$ million per quarter in 2010 , to $\$ 6$ million per quarter in 2011 and to $\$ 2.5$ million in each of the first three quarters of 2012. That is an overall decline of more than 80 percent. Pharmaceutical companies spend $\$ 60$ billion on physician marketing every year, and from 2009 to 2012, 15 drug makers spent more than $\$ 2$ billion in payments directly to physicians for consulting, research, travel, and promotional speaking. Critics say the talks are biased and may contribute to spiraling healthcare costs by promoting the use of more expensive brand name drugs over generics. They charge that such talks have led to off-label prescribing. Pharmaceutical companies ask physicians to speak on topics ranging from complex surgical procedures to the positive attributes of the companies' products. In return, speakers receive compensation in the form of honoraria and travel expenses. Depending on the meeting, physicians may speak on academic topics or may promote specific products. 
Ethical Issue: Speakers are likely to bias their presentations in favor of the sponsor's drugs.

Case Study 6 - Parke Davis Marketing Strategies

In 1996, Dr. David Franklin, an employee of the drug company Parke-Davis, filed the lawsuit under federal whistleblower statutes alleging that the company was illegally promoting an epilepsy drug for "off-label" uses through CME's, Conference calls among doctors and publication strategy. In 2004, the company, by then a division of Pfizer admitted guilt and agreed to pay $\$ 430$ million in criminal and civil liability related to promoting the drug for off-label use. Source: http://www.nbcnews.com/id/14348176/

The company used a variety of manipulative and fraudulent tactics to build sales of the drug, including:

* A "publication strategy" that allowed it to promote the drug by the massive distribution of articles written by technical writers hired by the company. These articles supposedly described the scientific evaluation of the drug for off-label uses. Parke-Davis paid honoraria to physicians for the use of their names on these articles, even though the physicians were not involved in preparing the articles (Ghost-Management).

* Holding "consultants"" meetings at which doctors were paid to hear - either from company employees or physician speakers hired by the company -- lengthy presentations relating to the drug, particularly regarding off-label usage. Parke-Davis also routinely tracked these "consultants'" drug prescription writing practices after these meetings (Data mining and Meetings).

* Payment of kickbacks to physicians to hear off-label promotion of the drug at programs billed as Continuing Medical Education (CME) seminars. Every aspect of these conferences and seminars was designed and approved by Parke-Davis, despite requirements that these sorts of seminars be developed independent of the drug manufacturer.

* Outright payments, in the form of grants, to reward demonstrated physicians who actively prescribed the drug (Financial Arrangements).

* The formation of a Speakers' Bureau, which paid physicians to give presentations advocating for the use of the drug.

As a result of this broad-ranging marketing scheme, sales of the drug in 2000 were 1.3 billion, and they grew to $\$ 1.7$ billion; nearly $80 \%$ of these sales were for off-label use.

Source: http://www.communitycatalyst.org/initiatives-and-issues/ initiatives/ prescriptionaccess-litigation/past-lawsuits/neurontin-off-label-promotions-case

In 2010, the case went to trial. Pfizer was found to have misrepresented the drug's effectiveness for off-label uses directly to doctors, sponsored misleading informational supplements and continuing medical education programs, suppressed negative information about the drug, and published articles in medical journals that reported positive information about its off-label effectiveness. The jury awarded the health insurer $\$ 47.3$ million in damages, and, the judge tripled the damages, for a total jury verdict of $\$ 142$ million.

Source: http://www.policymed.com/2014/01/supreme-court-rejection-of-pfizers-request-for-ricooff-label-review-could-open-floodgate-of-cases.html\#sthash. DArc5TrO.dpuf 


\section{Conclusions}

Ethical issues in the pharmaceutical sector are very complex, and may occur on all stages, from manufacturing to distribution and dispensing. In future ethics will be a major factor in decisionmaking. Thus, there will be a need to integrate ethics in all aspects of individual and organization functioning in pharma industry. Healthcare professionals and the pharmaceutical industry must work together to provide quality healthcare and this requires codes of ethics. The pharmaceutical sector suffers from a bad reputation, even though the intentions of the services and products offered are good - and can potentially mean the difference between life and death. Right to health is an ethical imperative and not an economic equation - solely pursuing profits at the expense of those who require access to essential life-saving medicines is morally wrong. Ethically compromised, uncontrolled practices within the medical and pharmaceutical sectors may need a careful reappraisal, and a regulatory restraint. As healthcare costs continue to climb and populations of people cannot pay for their needed medications, it is unacceptable for the pharmaceutical industry to frivolously spend on unethical marketing practices. Therefore, all healthcare practitioners must understand and avoid engaging in practices, which incur unnecessary costs and represent unethical practices for healthcare professionals. This chapter presented the ethical issues in pharmaceutical industry and the need for "systematic training in ethics" for all the stakeholders and the need for ethical leadership in an organization. Awareness and training of ethical guidelines are as important as company culture, business performance, industry and company regulations, and legal advice. Above all organizations must realize that the key to sustained growth in top and bottom line is ethical business practice.

\section{References}

[1] Bero LA,Rennie D (1996). Influences on the quality of published drug studies. International Journal Technical Assessment Health Care, 12: 209-37.

[2] Blumenthal D (2004). Doctors and Drug Companies. New England Journal of Medicine, 351(18):1885-1890

[3] Callaham M (2002). Journal prestige, publication bias, and other characteristics associated with citation of published studies in peer-reviewed journals. JAMA. 287:2847-2850.

[4] Davidson RA (1986). Source of funding and outcome of clinical trials. J Gen Intern Med.1:155158.

[5] Dickersin K (1990). The existence of publication bias and risk factors for its occurrence. JAMA. 263:1385-1389

[6] Djulbegovic B (2001). Acknowledgment of uncertainty: a fundamental means to ensure scientific and ethical validity in clinical research. Cur Oncol Rep, 3: 389-95.

[7] Djulbegovic B et al (2000). The uncertainty principle and industry-sponsored research. Lancet; 356: 635-8.

[8] Dwivedi G, Hallihosur S, Rangan L (2010). Evergreening: a deceptive device in patent rights. Technol Soc, 32:324-330.

[9] European Commission (2009). Pharmaceutical Sector Inquiry Report. http://ec.europa.eu/competition/sectors/pharmaceuticals/inquiry/communication_en.pdf.

[10] Faunce TA, Lexchin J (2007). 'Linkage' pharmaceutical evergreening in Canada and Australia. Aust New Zealand Health Policy, 4:8.

[11] Finucane TE (2004). Association of funding and findings of pharmaceutical research at a meeting of a medical professional society. Am J Med, 117:842-845

[12] Fugh-Berman A (2005). The Corporate Coauthor. J Gen Intern Med. 2005;20:p547. 
[13] Gaudry KS (2011). Evergreening: a common practice to protect new drugs. Nat Biotechnol, 29:876-878.

[14] Goldacre B (2012). Bad pharma. Fourth Estate, 2012.

[15] Hauck WW (1986). A proposal for interpreting and reporting negative studies. Stat Med, 5:203209.

[16] Hemphill CS, Sampat BN (2012). Evergreening, patent challenges, and effective market life in pharmaceuticals. J Health Econ, 31:327-339.

[17] Hughes D (2006). Less is more: medicines that require less frequent administration improve adherence, but are they better? PharmacoEconomics, 24:211-213.

[18] Hutchins M (2003). Extending the monopoly - how secondary patents can be used to delay or prevent generic competition upon expiry of the basic product patent. J Generic Med, 57:57-71.

[19] J. L. Klocke, Comment (2008). Prescription Records for Sale: Privacy and Free Speech Issues Arising from the Sale of De-Identified Medical Data," Idaho Law Review 44, no. 2, 511-536, 515.

[20] Koren G (1991). Bias against negative studies in newspaper reports of medical research. JAMA, 266:1824-1826.

[21] Lexchin J, Bero LA, Djulbegovic B, et al. Pharmaceutical industry sponsorship and research outcome and quality: systematic review. BMJ 2003; 326:116770. doi:10.1136/bmj.326.7400.1167

[22] McCarthy M (2000). Company sought to block paper's publication. Lancet, 356: 1659.

[23] McHenry L (2005). On the Origin of Great Ideas: Science and the Age of Big Pharma. Hast Cent Rep, 35: p17-19.

[24] Moghadam RG (2003). Scientific writing: a career for pharmacists. Am J Health Syst Pharm, 60(18):1899-900. [PubMed]

[25] Moher D et al (1999). Assessing the quality of reports of randomized trials: implications for the conduct of meta-analyses. Health Technol Assess, 3(12): 1-90

[26] Moher D et al (1998). Does quality of reports of randomized trials affect estimates of intervention efficacy reported in meta-analysis? Lancet, 352: 609-13.

[27] Nathan DG,Weatherall DJ (1999). Academia and industry: lessons from the unfortunate events in Toronto. Lancet, 353: 771-2.

[28] Perlis RH (2005). Industry sponsorship and financial conflict of interest in the reporting of clinical trials in psychiatry. Am J Psychiatry, 162:1957-1960.

[29] Randall $\mathrm{T}$ (1991). Kennedy hearings say no more free lunch or much else from drug firms. JAMA, 265: 440-441.

[30] Rennie D (1997). Thyroid storm. JAMA, 277: 1238-43.

[31] Rochon PA et al (1994). A study of manufacturer-supported trials of nonsteroidal antiinflammatory drugs in the treatment of arthritis. Arch Intern Med, 154: 157-63.

[32] Sackett DL, Oxman AD. HARLOT plc (2003). an amalgamation of the world's two oldest professions. BMJ, 327:1442-5.

[33] Sismondo Sergio (2008). Ghosts in the Machine: Publication Planning in the Medical Sciences. Social Studies of Science. 39: p171-198

[34] Smith R (2003). Medical Journals and pharmaceutical companies: uneasy bedfellows. BMJ, 326:1202-1205

[35] Smith R (2005). Medical Journals Are an Extension of the Marketing Arm of Pharmaceutical Companies. PLoS Medicine, 2(5): e138. http://medicine.plosjournals.org

[36] Studdert DM, Mello MM, Brennan TA (2004). Financial Conflicts of Interest in Physicians' Relationships with the Pharmaceutical Industry - Self-Regulation in the Shadow of Federal Prosecution. New Engl J Med, 351:1891-1900

[37] Turner EH, Matthews AM, Linardatos E, Tell RA, Rosenthal R (2008). Selective publication of antidepressant trials and its influence on apparent efficacy. $N$ Engl J Med, 358:252-260.

[38] Wand DR (1992). Pharmaceutical promotions a free lunch? N Engl J Med, 327: 351-53. 
[39] Wazana A (2000). Physicians and the Pharmaceutical Industry, Is a Gift Ever Just a Gift? Journal of the American Medical Assoc., 283(3):373-380

[40] Wertheimer AI, Santella TM (2009). Pharmacoevolution: the advantages of incremental innovation. Innovation and Health. London, UK: International Policy Network; 2009.

[41] Whitehead BJ, Kempner Stuart, Kempner R (2008). Managing generic competition and patent strategies in the pharmaceutical industry. J Intell Prop Law Pract, 3:226-235

*Corresponding author.

E-mail address: sasirekha.mba@ sairam.edu.in 